http://dx.doi.org/10.18232/alhe.951

Artículos

\title{
Crisis económicas en una economía pequeña y abierta: Ecuador, 1900-1999
}

\section{Economic Crisis in a Small Open Economy: Ecuador, 1900-1999}

Julio Oleas ${ }^{1, *}$ * (iD 0000-0002-1368-4638

${ }^{1}$ Instituto de Altos Estudios Nacionales, Quito, Ecuador.

*Correspondencia: juliooleas@yahoo.com

Resumen. Se analiza siete crisis económicas ocurridas entre 1900 y 1999. Se considera tres momentos, correspondientes a tres etapas del capitalismo en el siglo XX: la de la hegemonía de la Gran Bretaña y el patrón oro; la de la hegemonía de Estados Unidos y el patrón monetario del sistema de Bretton Woods, y, la de la globalización financiera, en las décadas finales del siglo. Se identifican las causas de las crisis y la forma de resolverlas (rupturistas o continuistas). Este trabajo podría servir de punto de partida para una investigación profunda y sistemática.

Palabras clave: capitalismo; dependencia; crisis; patrón oro; Bretton Woods; globalización.

Abstract. Analysis of seven Ecuadorean economic crisis, from 1900 to 1999. We assume three terms, belonging to three phases of $20^{\text {th }}$ Century capitalism: The Gold Standard and Great Britain hegemony, Bretton Woods and US hegemony, and globalization during the latest decades of the $20^{\text {th }}$ Century. In each term we identify the crisis causes and the way they were solved (continuist or rupture). This research could be a beginning of a more deep and accurate research.

CÓMO CITAR: Oleas, J. (2019). Crisis económicas en una economía pequeña y abierta: Ecuador, 1900-1999. América Latina en la Historia Económica, 26(2), e951. DOI: 10.18232/alhe.951 
Key words: capitalism; dependency; crisis; gold standard; Bretton Woods; globalization.

JEL: N16; N46.

Recibido: 12 de enero de 2018.

Aceptado: 24 de julio de 2018.

Publicado: 16 de enero de 2019.

INTRODUCGIÓN: CRECIMIENTO, CRISIS Y MACROECONOMÍA

En América Latina los ciclos de crecimiento económico por lo general terminan en eventos de crisis - etapas de inflexión o transición- que dificultan el avance hacia el desarrollo ${ }^{1}$ Esto se traduce en volatilidad, causada por los ciclos del comercio internacional, cambios demográficos o tecnológicos y flujos de capital. Perfiles de inserción internacional basados en recursos naturales "expuestos a cambios muy bruscos, tanto de oferta como de demanda, han mostrado una volatilidad de precios muy alta" (Bértola y Ocampo, 2013, p. 33) que, conjugados con canastas de exportación poco diversificadas, complican la gestión macroeconómica y la capacidad de adaptación al cambiante escenario mundial. Flujos internacionales de capital procíclicos provocan una volatilidad mayor a la que sería de esperar (Bértola y Ocampo, 2013).

En la región estas coyunturas transicionales y su sobrevolatilidad han sido objeto prioritario de estudio. H. W. Singer (1950) asevera que el comercio internacional "es de importancia muy considerable [...] y los beneficios que ellos [los países subdesarrollados] obtienen del comercio y cualquier variación de este afectan profundamente su ingreso nacional" (p. 473). Urquidi y Thorp (1976) afirman que "las relaciones externas han constituido un problema esencial del desarrollo económico latinoamericano” (p. 11). Salgado (1978), economista ecuatoriano de raigambre cepalina, argumenta que "hasta ahora todas las posibilidades de expansión de la economía [ecuatoriana] han dependido de [las] exportaciones. Ellas significan movimiento y dinamismo. Son como las velas de un navío que se hinchan con los vientos del mundo para impulsar el casco. Este, sin ellas, podría flotar, pero no avanzar" (pp. 26-27). Bértola y Ocampo (2013) puntualizan que las "crisis se producen por fuertes caídas de las exportaciones en medio de coyunturas internacionales críticas $[. .$.$] que generan fuertes deterioros de los precios de productos básicos y se traducen, a su vez,$ en saldos negativos de las balanzas comerciales" (p. 37).

De acuerdo con Reinhart y Rogoff (2009), Bértola y Ocampo (2013) aceptan que las crisis pueden ser cambiarias, de deuda externa o bancarias (p. 36), lo que refiere al síntoma (la devaluación, el default de pagos o el pánico bancario) y no a sus causas originarias, y supone la pérdida temporal del equilibrio - la situación normal de la economía, según el pensamiento tradicional. ¿Cuán intensos deben ser los eventos naturales o políticos que alteran ese supuesto equilibrio, para considerarlos constitutivos de una crisis, es decir, de una coyuntura en la que se produce una inflexión macroeconómica?

Por su parte, la epistemóloga María L. Svampa (2016) afirma que crisis es un concepto que ha sufrido blanqueamiento semántico, es decir, la pérdida de connotaciones precisas y "un amortiguamiento debido a la variedad de sus usos en el plano médico, económico y político, entre otros” (p. 139). Reinhart Koselleck sugiere que en "un espacio político secularizado, todas las tintas [de

\footnotetext{
${ }^{1}$ Se asume que avanzar hacia el desarrollo es reducir en forma constante y significativa las brechas sociales y económica entre países subdesarrollados y desarrollados.
} 
las crisis] se cargan sobre la acción de los agentes políticos" (citado en Svampa, 2016). La voz crisis, en general ¿es "una experiencia que remite a la unicidad o a la repetición”? En el primer caso, "implicaría [...] un tono más dramático, que ilustra una situación luego de la cual nada volverá a ser igual" -un resultado rupturista. En el segundo, el tiempo histórico sería circular - un resultado continuista (Svampa, 2016, p. 145).

Fuera de la tradición de la economía del equilibrio se afirma que el capitalismo depende de las crisis y que, en consecuencia, no serían situaciones excepcionales. James O'Connor (1988) precisa esta idea proponiendo que las crisis operan como un mecanismo económico disciplinario, aprovechadas por el capital para reestructurarse y restaurar su capacidad de acumulación y explotación del trabajo 2 Serían, entonces, consustanciales a este modo de producción.

Esta investigación analiza varias crisis ocurridas en el siglo xx, agrupadas en tres etapas: la del capitalismo del patrón oro (hasta 1932), la del capitalismo de Bretton Woods (décadas de 1940 hasta 1980), y la del capitalismo especulativo (décadas de finales del siglo xx), con el objetivo de caracterizar esos eventos de crisis, considerándolos como coyunturas transicionales -rupturistas o continuistas.

Estas reflexiones conducen a una tercera deliberación. Para la macroeconomía convencional la crisis es el resultado del debilitamiento de la demanda agregada asociada a situaciones de alto desempleo involuntario. Esto ocurre en economías con profundos y variados mercados internos, como los de los países capitalistas centrales. Este supuesto no es tan realista en la mayoría de países en desarrollo. En el caso de Ecuador, la conformación de los mercados internos ha sido un difícil proceso que todavía no habría concluido. Los factores determinantes del proceso de crecimiento no han sido los relativos al consumo interno, sino los relacionados al sector externo, como sugiere la elegante alegoría de Germánico Salgado. En este sentido, el Ecuador del siglo xx bien puede caracterizarse como un país que atravesó sucesivos auges de monoexportación alterados por crisis cambiarias, tecnológicas, fiscales o especulativas, que también afectaron al consumo interno y que no en todos los casos se resolvieron mediante transiciones rupturistas.

\section{EL PATRÓN ORO Y LAS CRISIS CAMBIARIAS}

En la era del patrón oro la moneda de un país podía ser canjeada por oro (amonedado o en barras) o por giros-oro (por lo general sobre Londres o Nueva York), a una relación de cambio previa fija. Este patrón fue instituido en Ecuador, por primera vez, mediante un acuerdo de caballeros negociado en Guayaquil en 1897, ratificado mediante la promulgación de la ley de monedas del 4 de noviembre de 1898 (Carbo, 1978, p. 51). Este sistema cambiario estuvo vigente hasta julio de 1914, y su finalización es materia del primer evento de crisis analizado.

Con la revolución Juliana (1925), y tras una década de moratoria y medio siglo de libertad bancaria, en 1927 se fundó el Banco Central del Ecuador (BCE), como una caja de conversión que reinstauró un patrón oro de cambio. Por ley el BCE debía mantener una paridad cambiaria fija, a razón de cinco sucres por dólar oro que, en la Gran Depresión, condujo al país a una aguda crisis deflacionaria, materia del segundo evento analizado.

${ }^{2}$ Traducción del autor del texto original en inglés. 
El fin del primer patrón oro y la moratoria de 1914

Entre 1890 y 1920 Ecuador experimentó un extraordinario auge económico liderado por la exportación de cacao. En 1894 produjo 28.3 \% de la producción mundial, pero para 1903 "la cosecha ecuatoriana representaba apenas 18.3\%” (Alexander, 1992, p. 124). Al cambiar el siglo, Brasil y San Tomé eran los dos principales competidores del cacao ecuatoriano en un mercado mundial controlado por los centros de demanda y sus entidades financieras.

Como piedra angular de este auge, el 29 de noviembre de 1897 se firmó un acuerdo entre exportadores, importadores y banqueros, que fijó el tipo de cambio en diez sucres por libra esterlina. El Banco de Inglaterra era el centro de la gestión del sistema monetario internacional de esa época. Entre 1900 y 1913 el público confió en el patrón oro administrado por los bancos guayaquileños. La estabilidad cambiaria ayudó a regular la balanza comercial: entre el 1 de enero de 1900 y el 31 de diciembre de 1913 se importaron 18300000 sucres oro -correspondientes en su mayoría a ingresos por exportaciones de cacao- y se exportaron 12100000 -para pagar importaciones de todo tipo (Oleas, 2004, p. 433). El auge cacaotero impulsó una tasa anual de crecimiento del PIB estimada en cinco por ciento $]^{3}$

Al estallar la primera gran guerra europea, el 28 de julio de 1914, el Banco de Inglaterra suspendió la convertibilidad de la libra esterlina. Esto interrumpió el comercio internacional y marcó el inicio de la crisis. Tras la interrupción de los circuitos comerciales, la agresiva propagación de las plagas en las plantaciones ecuatorianas (escoba de bruja y monilia) provocó el colapso del ciclo del cacao.

En medio de la especulación y la incertidumbre, mediante decreto ejecutivo del 6 de agosto de 1914, menos de diez días después de iniciada la guerra, el presidente Plaza suspendió "el cambio de billetes con oro, en los bancos de toda la República, por el término de treinta días, a fin de evitar los fraudes en la exportación de oro"; también prohibió "toda nueva emisión de billetes" y la exportación de oro (Carbo, 1978, p. 71). El gobierno respaldó los billetes de los bancos de emisión, pero se les prohibió hacer nuevas emisiones 4

Este decreto fue llamado Ley Moratoria, ratificada por el Congreso el 30 de agosto de 1914, prorrogada "mientras puedan normalizarse las operaciones bancarias y de importación y exportación” (Carbo, 1978, p. 72). El Congreso confirmó el decreto de Plaza hasta cuando se normalizase el comercio exterior, con lo que una moratoria que inicialmente debía durar 30 días terminó extendiéndose por más de una década.

La crisis comercial fue atenuada con la garantía pública a los billetes emitidos por las entidades privadas. Pero luego de la moratoria cambiaria los bancos reaccionaron según sus propios intereses. El Banco del Ecuador siguió convirtiendo sus billetes por oro, aduciendo que la ley no prohibía canjear billetes, sólo los autorizaba a no hacerlo. El Banco Comercial y Agrícola, con una cartera de clientes distinta, se convirtió en el principal agente financiero de los gobiernos de la bancocracia 5

\footnotetext{
${ }^{3}$ En América Latina el crecimiento de la economía ecuatoriana sólo fue inferior al crecimiento de Argentina, de $6.3 \%$ (Oleas, 2004, p. 435).

${ }^{4}$ Los considerandos del decreto contemplaron: el efecto adverso de la guerra europea para la economía ecuatoriana, el bloqueo de las reservas oro de los bancos ecuatorianos en los países europeos y en Estados Unidos y la obligación de mantener reservas oro para respaldar la emisión de billetes.

${ }^{5}$ Según Chiriboga (2013), la mayoría de accionistas del Banco Comercial y Agrícola tenía intereses en los negocios de exportación, mientras que en el Banco Central del Ecuador predominaban los accionistas con intereses en negocios de importación.
} 
Entre 1914 y 1925 el crecimiento de los precios experimentó una variación absoluta de $145 \%$. La población se empobreció y la protesta social recrudeció, pero fue reprimida con dureza $\sqrt{6} \mathrm{La}$ política fiscal de los gobiernos liberales y a la expansión de la oferta monetaria de los bancos de emisión agravaron las consecuencias de la crisis. En 1925, antes de la revolución Juliana, el Banco Comercial y Agrícola emitió $71.5 \%$ del valor total de los billetes en circulación, con un respaldo oro de $14 \%$. Desde el inicio de la moratoria el total de la circulación monetaria se triplicó; en el caso de la emisión del Comercial y Agrícola, era prácticamente fiduciaria (véase cuadro 1).

El valor de las exportaciones de cacao se redujo de casi 10000000 de dólares en 1915 a 5500000 en 1926 (Alexander, 1992, p. 128). Para contrarrestar esta tendencia se devaluó la moneda, levemente hasta 1918 y más rápidamente entre 1920 y 1924 . Esta decisión permitió mantener en sucres los ingresos de los exportadores, pero contribuyó a incrementar los precios y trasladó el costo de la crisis a la población (Oleas, 2004, p. 439). A pesar del encarecimiento de las importaciones, las reservas oro de los bancos de emisión bajaron de 60 a $26 \%$ en relación con los billetes en circulación y la deuda del gobierno con los bancos guayaquileños subió de 10000000 de sucres a más de 33000000 (véase cuadro 1).

Esta crisis rompió la estabilidad cambiaria proporcionada por el patrón oro, y se prolongó más de una década, hasta el 23 de junio de 1926, cuando se prohibió a los bancos particulares emitir nuevos billetes y se transfirió el oro y la plata que los respaldaban a la Caja Central de Emisión y Amortización (Oleas, 1995, p. 10). Un año antes, el 9 de julio de 1925, varios militares constituyeron una junta militar de gobierno que transfirió el poder a otra junta provisional que creó la Caja Central de Emisión y Amortización, entidad predecesora del Banco Central del Ecuador (вСE), encargada de retirar de circulación los billetes emitidos por los bancos comerciales y de preparar el camino para monopolizar la emisión monetaria y centralizar el mercado cambiario 7

\section{El segundo patrón oro y la crisis deflacionaria de 1927-1931}

El BCE se fundó el 10 de agosto de 1927. Edwin Walter Kemmerer recomendó establecer una entidad autónoma de derecho privado, cuyo objetivo central sería velar por la estabilidad cambiaria. Durante 52 meses este banco operó como una caja de conversión: el valor del sucre se fijó en 0.300933 gramos de oro fino, equivalente a una quinta parte del dólar oro de la época. Con este respaldo metálico se asumió un tipo de cambio fijo de cinco sucres por dólar ${ }^{8}$

En condiciones externas adversas, la rigidez cambiaria de la regla de conversión produjo estancamiento del sistema productivo y deflación general de precios. Al finalizar 1931 la oferta monetaria bajó a un mínimo de 37000000 de sucres, es decir, una reducción absoluta del circulante

\footnotetext{
${ }^{6}$ El más conocido evento represivo ocurrió en Guayaquil, el 15 de noviembre de 1922, durante el gobierno de José Luis Tamayo, quien asumió la presidencia con el auspicio del Banco Comercial y Agrícola. Noventa años de la masacre (16 de noviembre de 2012). El Telégrafo.

${ }^{7}$ La junta provisional estuvo integrada por Luis N. Dillon, José Rafael Bustamante, Francisco Boloña y los generales Francisco Gómez de la Torre y Moisés Oliva.

${ }^{8}$ El patrón oro vigente entre 1898 y 1914 estuvo referido a la libra esterlina, mientras que el patrón oro del BCE, vigente entre agosto de 1927 y febrero de 1932, se hizo operativo en relación con el dólar estadunidense. Para este último, el tipo de cambio inicial benefició a los exportadores y a los deudores del sistema financiero; mientras que asalariados, empleados del sector público y jornaleros inmediatamente percibieron el perjuicio: si en 1914 el jornal equivalía a 60 centavos de dólar oro, en 1927 valía sólo 40 centavos de dólar, es decir 33 \% menos (Oleas, 1995, p. 12).
} 


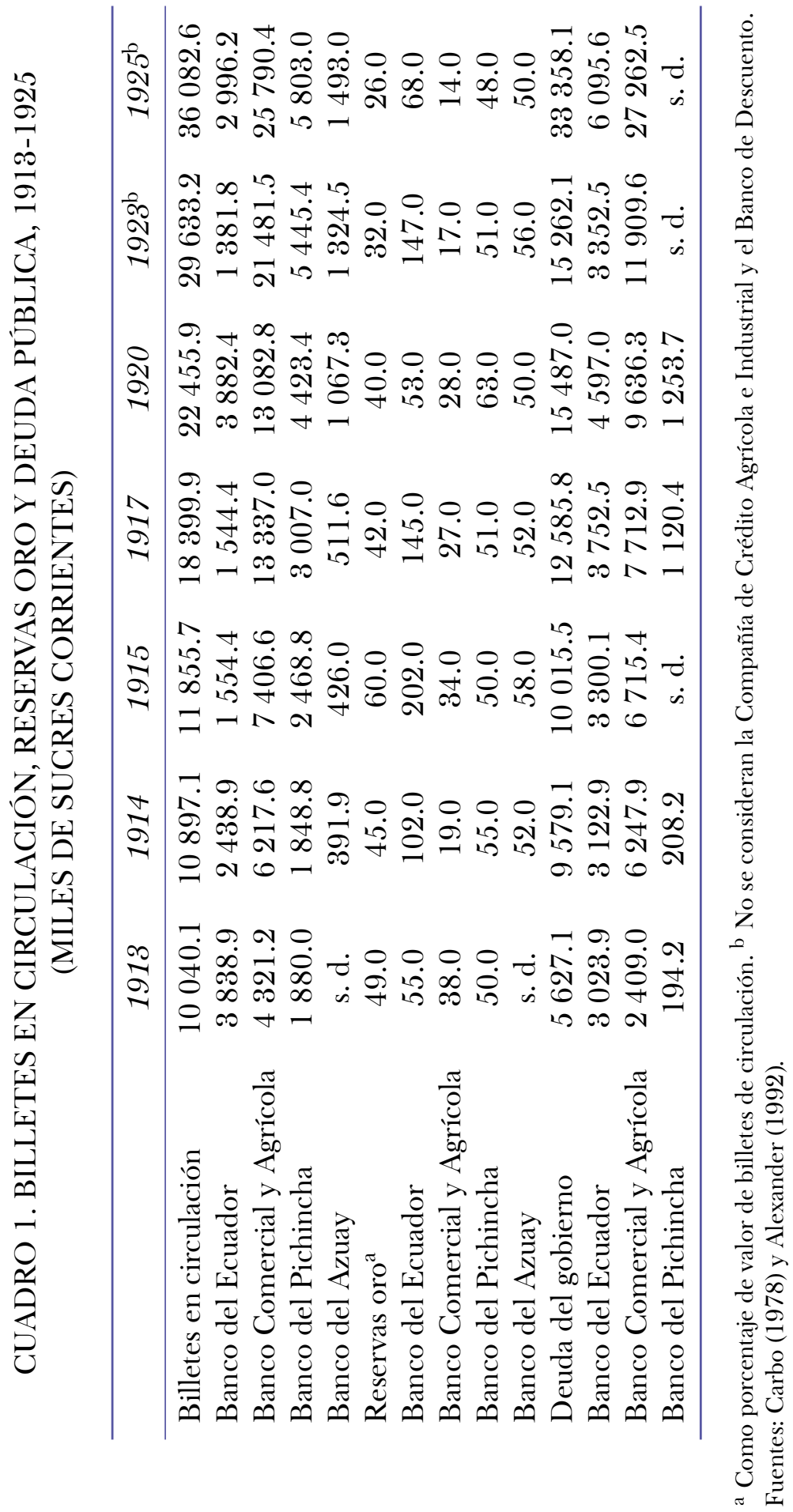




\section{CUADRO 2. INDICADORES ECONÓMICOS 1927-1937}

\begin{tabular}{cccccc}
\hline & Balanza comercial $^{\mathrm{a}}$ & M1 $^{\mathrm{b}}$ & Reservas oro $^{\mathrm{b}}$ & Indice de precios & Variación anual IP $^{\text {Res }}$ \\
\hline 1927 & 7809 & 65 & 44 & 169.7 & -6.9 \\
1928 & 3150 & 65 & 38 & 138.9 & -18.1 \\
1929 & 193 & 57 & 35 & 144.3 & 3.9 \\
1930 & 3300 & 45 & 29 & 143.3 & -0.7 \\
1931 & 2470 & 37 & 15 & 106.4 & -25.8 \\
1932 & 2130 & 56 & 17 & 100.9 & -5.2 \\
1933 & 2025 & 82 & 18 & 134.5 & 33.3 \\
1934 & 2511 & 103 & 27 & 185.6 & 38.0 \\
1935 & 1172 & 100 & 39 & 180.5 & -2.7 \\
1936 & 2489 & 127 & 43 & 220.3 & 22.0 \\
1937 & 2093 & 138 & 39 & 264.1 & 19.9 \\
\hline
\end{tabular}

${ }^{\mathrm{a}}$ Dólares estadunidenses x $1000 .{ }^{\mathrm{b}}$ Saldo, millones de sucres.

Fuente: Banco Central del Ecuador (1997).

equivalente a $43 \%$, en relación con el saldo de la oferta monetaria de 1927, año inicial de operaciones del BCE (véase cuadro 2). El índice de precios al consumidor tuvo tasas decrecientes en 1927-1928 y en 1930-1932, llegando en 1931 a registrar una deflación de 25.8 por ciento.

Entre agosto de 1927 y enero de 1932 el BCE se concentró en defender el tipo de cambio (cinco sucres por dólar), a costa de la pérdida del control de la oferta monetaria y de la reducción de las reservas internacionales, que llegaron a un saldo mínimo de 15000000 de sucres en 1931, es decir $65.1 \%$ menos que el saldo registrado el primer año de su operación. Esta crisis deflacionaria afectó a todos los sectores económicos del país y se hizo insostenible cuando el Banco de Inglaterra decidió suspender la convertibilidad de su moneda por oro el 21 de septiembre de 1931. Esto ocasionó el congelamiento de cerca de 7000000 de sucres oro depositados por el BCE en ese banco. La reserva monetaria bajó a menos de 50 \% de la oferta monetaria (Oleas, 1995, p. 16). Bajo esas condiciones, si se decidía respetar la relación de respaldo legal, hubiera sido necesario extraer más circulante, agravando la crisis deflacionaria.

$\mathrm{Al}$ mantener la regla cambiaria fijada por Kemmerer, el BCE condujo al país a la peor crisis recesiva de su historia. Cuando en enero de 1932 la reserva legal del BCE bajó a menos de 14000000 de sucres, el presidente encargado, Baquerizo Moreno, promulgó varios decretos supremos que cambiaron las reglas monetarias: el número 32, para restablecer la inconvertibilidad; el número 33, que obligaba al BCE a conceder al gobierno un préstamo por 15000000 de sucres $\sqrt[9]{9}$ y el número 34, exonerando de tasas portuarias a las exportaciones. El más cuestionado de estos fue el que ordenó conceder crédito al gobierno. Como el directorio del BCE no accedió de inmediato, el ejecutivo emitió un nuevo decreto, el número 56, ordenando la intervención del instituto emisor. Esta crisis política se resolvió en Guachalá, hacienda de propiedad de Neptalí Bonifaz (primer presidente del directorio del BCE y candidato a la presidencia de la república), morigerando los requerimientos de Baquerizo. Pero este arreglo no evitó la especulación cambiaria, que trató de controlarse con un nuevo decreto, el número 90 de abril de 1932, de incautación de cambios, a

${ }^{9}$ Más de $100 \%$ de la reserva oro, o $40 \%$ del saldo de M1 registrados en 1931. 
una cotización oficial de 5.95 sucres por dólar, lo que oficializó una devaluación de 19 \% respecto al tipo de cambio de la convertibilidad. El BCE fue autorizado a negociar giros sobre el exterior o, en caso de escasez, a priorizar su uso.

Estos cambios de política rompieron con la independencia del BCE y terminaron definitivamente con el segundo patrón oro. Pero facilitaron la recuperación del sector externo de la economía, lo que se reflejó en los saldos de la balanza comercial y en las reservas oro, que experimentaron incrementos constantes hasta 1936. Pero la oferta monetaria, que bajó a un mínimo de 37000000 de sucres en 1931, se cuadruplicó hasta 1937, impulsando el incremento de los precios (véase cuadro 2).

\section{LAS CRISIS EN LA ERA DE BRETTON WoOdS}

El orden internacional de la segunda posguerra obedeció a los designios de Estados Unidos, lo que se expresó en los acuerdos de Bretton Woods que crearon el Fondo Monetario Internacional (FMI) y el Banco Mundial (originalmente el Banco Internacional de Reconstrucción y Fomento [BIRF]), así como un nuevo sistema monetario internacional basado en el dólar estadunidense con respaldo oro.

Durante tres décadas se generalizó la idea de que la industrialización era la única forma de alcanzar el desarrollo. En América Latina, la política de la Comisión Económica para América Latina y el Caribe (CEPAL) estuvo enfocada hacia ese objetivo. Pero Ecuador, dada la situación de su economía al final de la década de 1940, recibió el consejo de incursionar en algún cultivo de exportación para generar los niveles de acumulación de capital necesarios para, posteriormente, intentar su industrialización, como ya la habían iniciado Brasil, Argentina, México, Colombia y Chile, antes incluso de que la CEPAL teorizara sobre esa estrategia. Ese cultivo fue el banano, protagonista de un nuevo auge exportador interrumpido en 1965 por varios cambios promovidos por las empresas transnacionales estadunidense en Centroamérica.

En el caso ecuatoriano la industrialización dirigida por el Estado se intensificó en la década de 1970, gracias a un nuevo auge exportador que incrementó la dependencia externa del país. ${ }^{10}$ En 1975, en parte por el forcejeo de la dictadura de Rodríguez Lara con el consorcio Texaco-Gulf, la principal empresa extractora de petróleo, y en parte por la presión de los grupos importadores por lograr una mayor participación en la renta petrolera, se produjo una nueva crisis. Ya terminado el auge petrolero, en la década perdida de 1980, ocurrió otro evento crítico (el quinto de este estudio), en el que confluyeron factores políticos, estructurales y naturales.

\section{Los cambios tecnológicos en el mercado mundial de banano}

Al final de la década de 1940 se intensificó el cultivo de banano, aprovechando las condiciones naturales de las planicies costeras, las capacidades instaladas dejadas por el ciclo monoexportador del cacao y la bonanza externa de la segunda postguerra europea. En 1955 Ecuador ya era el pri-

\footnotetext{
${ }^{10}$ También causó la enfermedad holandesa. Según Naranjo (2006), p. 69, este término fue utilizado por la revista The Economist en 1977, para describir los fenómenos de desindustrialización en Holanda. En la década de 1960 del siglo pasado "se pensó que la explotación de los grandes yacimientos de gas natural descubiertos por Holanda, cerca del Mar del Norte, llevaría a su enriquecimiento generalizado.” Pero no ocurrió así. "El gran aumento de sus ingresos externos causó la apreciación de su moneda, la destrucción de su industria y agricultura, y el empobrecimiento de vastos sectores del país" (Sardi, 2012). El primer estudio académico sobre enfermedad holandesa se debe a Corden y Neary (1982).
} 
mer proveedor internacional, con una participación de $20 \%$ de las exportaciones mundiales. Una década más tarde, en 1965, se disponía de 175361 hectáreas en producción, en 2592 unidades agrícolas distribuidas en todas las provincias de la Costa (Larrea, 1987).

La expansión del cultivo propició la propagación del mal de Panamá ${ }^{11}$ El $90 \%$ de la fruta exportada era vendida a ocho empresas, capaces de fijar los precios internos 12 Desde 1962 se exportó solo la mitad de la producción, lo que contribuyó a que los exportadores mantuvieran deprimidos los precios internos, incrementando su participación en el valor agregado total generado en el proceso de producción-exportación. Así, en menos de dos décadas, Ecuador se transformó en país bananero.

Durante las décadas de 1950 y 1960 el banano representó en promedio casi 50 \% de las exportaciones totales. Hasta 1964, 60 \% de la fruta exportada se dirigió a Estados Unidos, donde el producto ecuatoriano competía exitosamente con la fruta centroamericana (Oleas, 2004, p. 450). En la década de 1960 el mercado mundial experimentó una fuerte sobreoferta y las exportaciones ecuatorianas retrocedieron. "Las ventas del Ecuador a Estados Unidos se redujeron a la mitad entre 1964 y 1973, mientras en el caso europeo la declinación fue menor" (Larrea, 1987, p. 56).

A esto se sumaron varios cambios tecnológicos en el mercado mundial. La United Fruit introdujo el Cavendish, variedad de la fruta más resistente a las plagas y con una productividad superior al Gros Michel. Ecuador producía esta última; era una planta más alta, pero con un racimo menos voluminoso y más propensa a contraer la sigatoka y el mal de Panamá. Si no se reconvertían las plantaciones a la nueva variedad, el país quedaría fuera del mercado. Además, las transnacionales modificaron la tecnología de transporte, de racimos a cajas de cartón, y establecieron estándares fitosanitarios más exigentes. El Cavendish, desarrollado en Honduras por la United Fruit, es una variedad inmune al mal de Panamá, tiene un tallo más pequeño y, sin embargo, produce un racimo más grande.

El ministro de Fomento José Cárdenas contrató:

[...] con proveedores privados la compra de colinos cuyo transporte correría por cuenta de ellos mismos hasta su entrega en Guayaquil. Según recuerdo, el costo total de la negociación ascendía a unos 15000 dólares y se trataba del viaje de un avión DC-3. La operación se hizo con todo éxito y la propagación geométrica de los colinos [...] permitió la repoblación en un corto número de años. Esto es, entre 1964 y 1966, el Ecuador se vio enfrentado al problema de tener que cambiar sus plantaciones para mantenerse en la competencia y conservar su presencia como líder en el mercado bananero mundial (Cárdenas, 1995, p. 66).

A pesar de la reacción de Cárdenas y de los bananeros, empeñados en la rápida reconversión tecnológica de procesamiento de la fruta para su exportación y en la reposición de las plantaciones con los colinos traídos de Honduras ${ }^{13}$ en 1965 el déficit comercial subió a 31700000 dólares y el crecimiento de 1966 fue de apenas 2.4\%. En 1965 el valor de las exportaciones de banano cayó más de $25 \%$, por primera vez desde 1946. Entre 1965 y 1966 el precio de la fruta ecuatoriana fue el más bajo de la década y el déficit comercial subió a casi $3 \%$ del PIB (véase cuadro 3 ).

\footnotetext{
${ }^{11} \mathrm{El}$ mal de Panamá o fusariosis es una enfermedad fungosa que ataca las raíces de algunas variedades de banano.

${ }^{12}$ Las principales, según su participación en el mercado de exportación en 1964, eran la Standard Fruit Co. (16.8\%), Noboa S. A. (16\%), United Fruit Co. (14.7\%), Ubesa (14\%), Grupo Alemán (12.1\%), Bananas S. A. (6.3\%), Agrícola San Vicente (5.5\%), Frutera Sudamericana (4.9\%), y otras 23 empresas (11.5\%) (Banco Central del Ecuador (1997)).

${ }^{13}$ Se conoce como colino a la raíz fibrosa que crece del tallo subterráneo de esa planta herbácea.
} 
Esta crisis de cuenta corriente se superó gracias a la audacia de los productores, auspiciados por un prestante funcionario público. El sector privado asumió el reto reconvirtiendo las áreas productivas e invirtiendo en los cambios tecnológicos requeridos por el mercado mundial. Entre 1965 y 1970 se erradicaron unas 70000 hectáreas de Gros Michel, se sembraron 50000 hectáreas de Cavendish, el país siguió compitiendo y la política macroeconómica continuó bajo los mismos criterios acordados para los países periféricos en el consenso de Bretton Woods. Pero las ventas de banano a Estados Unidos bajaron de 524000 toneladas métricas en 1964 a $274000 \mathrm{Tm}$ en 1973, y la Standard Fruit y United Fruit retomaron el liderazgo (Oleas, 2004, p. 452). Luego de 1966 el banano siguió siendo el rubro de exportación más importante. Pero el esfuerzo no fue suficiente. Los gobiernos de la segunda mitad de la década de 1960 -la junta militar, Clemente Yerovi y José María Velasco Ibarra- sufrieron un creciente e inusual déficit comercial provocado por los requerimientos de la inversión necesaria para iniciar la era del petróleo (véase cuadro 3 ).

\section{La enfermedad holandesa}

Ecuador inició la exportación de petróleo en agosto de 1972 14 Aunque las expectativas nacionales eran muy altas y positivas, las dificultades para aprovechar el nuevo auge fueron considerables, dado el extraordinario cambio de magnitudes que significó el auge petrolero para un país que no había modernizado la institucionalidad heredada de la revolución Juliana.

Con la nueva bonanza nadie pudo anticipar que, pocos meses después de iniciada, el país sufriría una aguda crisis de la cuenta corriente, que alteró la política económica y propició el relevo del gobierno militar. Esta crisis sirvió de punto de partida para relajar el control del endeudamiento externo, congelar los salarios hasta 1979 y endurecer la política laboral. El fácil financiamiento internacional apalancado por la riqueza petrolera contribuyó a mantener la política industrial, a pesar de la creciente carga que irrogaba a la cuenta corriente la importación de materias primas. El petróleo también permitió sostener fijo el tipo de cambio en 25 sucres por dólar.

El auge petrolero marcó un hito en la historia económica de Ecuador. Cuando comenzó la exportación de crudo, el barril se cotizaba en 2.8 dólares; este precio se duplicó en 1973, se quintuplicó en 1974 y se estabilizó en 1975 en 14.3 dólares por barril hasta 1978; en 1979 nuevamente escaló a 25.9 y una vez más, en 1980, a 39.5 dólares. Ni el gobierno ni el sector privado estuvieron preparados para absorber este flujo de ingresos: las exportaciones de crudo pasaron de poco más de 1000000 de dólares en 1971 a 1393000 en 1980 (véase cuadro 4).

La absorción de la economía ecuatoriana, que se había mantenido por sobre el $100 \%$ hasta 1972, debido al gasto de inversión requerido para iniciar la explotación petrolera, bajó en 1973 a $88.1 \%$ debido a la incapacidad institucional para canalizar las nuevas rentas y a la carencia de proyectos de desarrollo en los cuales se debía "sembrar el petróleo". Fue necesario que la Junta Nacional de Planificación reformule la planificación nacional para ampliar y acelerar la industrialización, recapitalizar al Banco Nacional de Fomento y a la Corporación Financiera Nacional, crear nuevos mecanismos para la inversión privada, expandir los subsidios a la población, crear empresas de economía mixta y preparar proyectos de inversión. Estos cambios sólo comenzaron a concretarse desde el segundo semestre de 1974, con lo que la absorción se recuperó a $99.4 \%$ y en 1975 sobrepasó el $100 \%$, con tasas de inversión superiores a $23 \%$ del PIB, según requería la industrialización sustitutiva (véase cuadro 5 ).

\footnotetext{
${ }^{14}$ Ecuador extrajo petróleo de la península de Santa Elena desde la segunda década del siglo xx, pero en la década de 1970 las reservas de esos campos ya se habían agotado y las exportaciones eran minúsculas.
} 


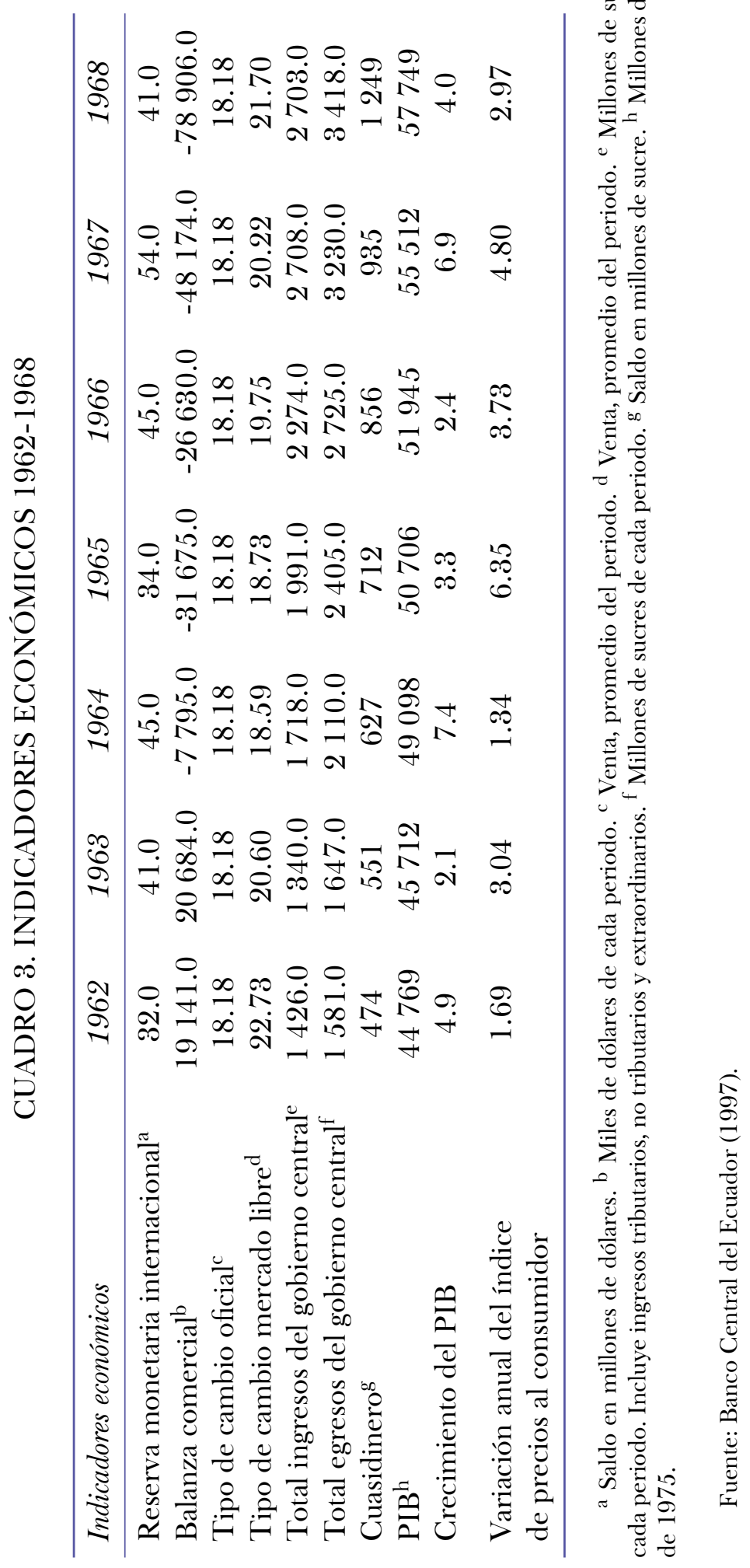




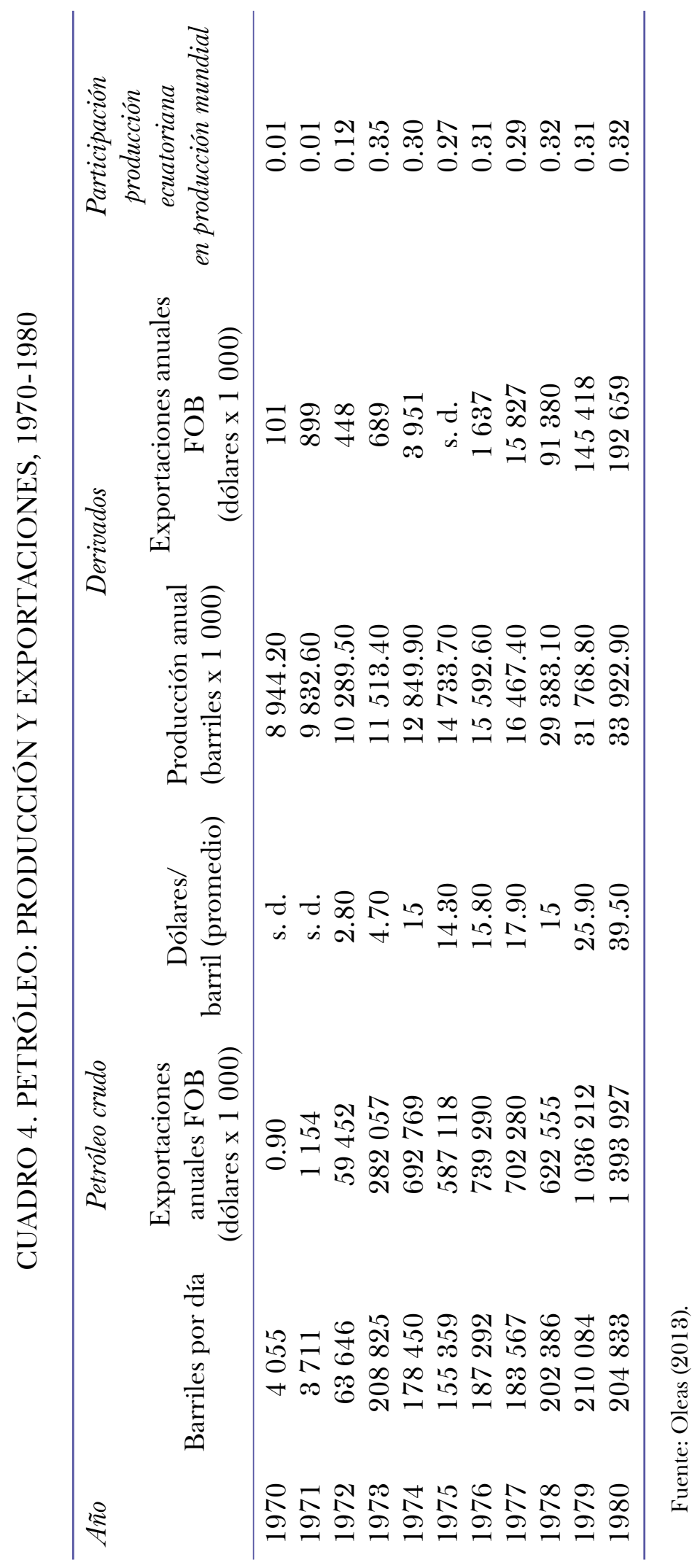




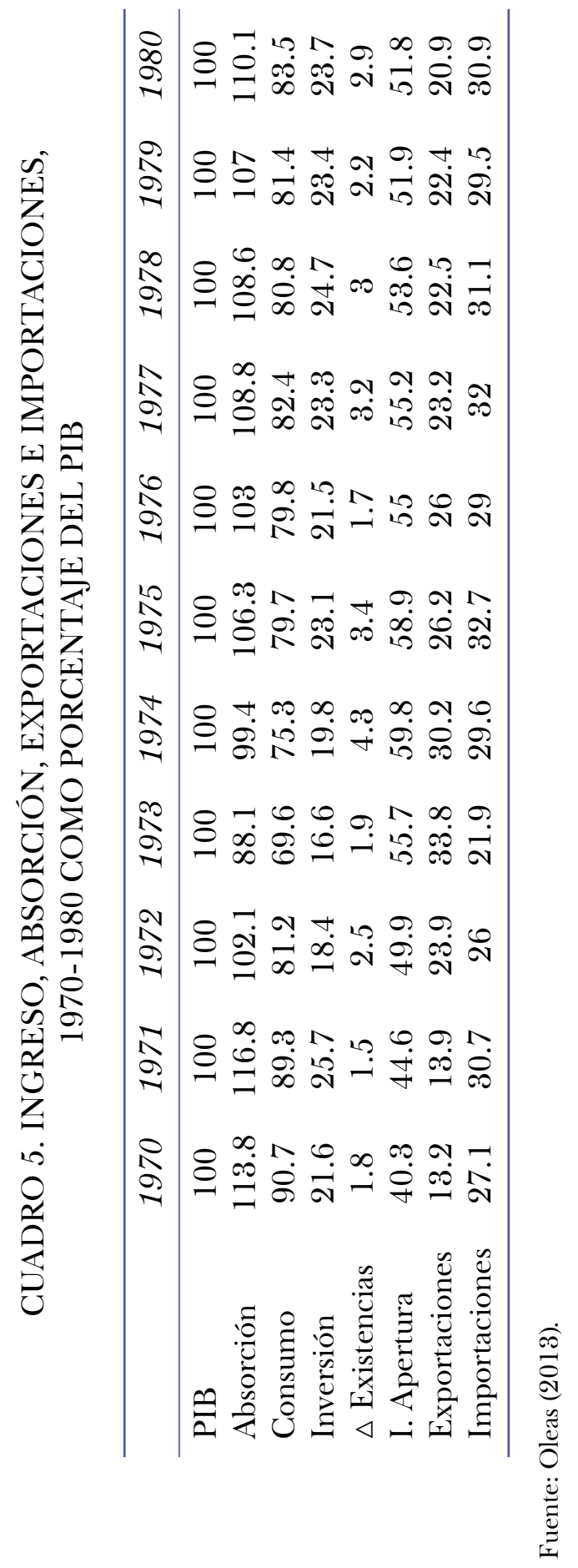


La balanza comercial, negativa desde 1964, se tornó superavitaria en 1972. Entre 1972 y 1974 las exportaciones FOB de petróleo se multiplicaron por 2.45 veces (véase cuadro 4 ) y, sin embargo, en 1975 el déficit comercial regresó a las cuentas del sector externo y el saldo en cuenta corriente nuevamente fue negativo. Ese año las exportaciones de petróleo representaron $65.4 \%$ del valor total exportado, mientras que las importaciones de materias primas representaron $39.8 \%$ y las de bienes de capital $47.5 \%$ del valor total importado. El índice de apertura económica bordeó por primera vez $60 \%$ del PIB (véase cuadro 5 .

La riqueza petrolera incentivó el crecimiento de la oferta monetaria. El medio circulante pasó de 7423 millones de sucres en 1972 a 15539 millones en 1975. La inflación se aceleró y, como al mismo tiempo el tipo de cambio se mantuvo fijo en 25 sucres por dólar, la apreciación del tipo de cambio real abarató las importaciones (Oleas, 2013, pp. 54, 402).

Mientras tanto, la dictadura de Rodríguez Lara disputaba el control del sector petrolero al consorcio Texaco-Gulf. El ministro de energía, contralmirante Gustavo Jarrín Ampudia, propuso a la Corporación Estatal Petrolera Ecuatoriana (CEPE) comprar 51 \% de las acciones del consorcio. La Texaco-Gulf respondió con un boicot: mientras en 1974 se extrajeron 178450 barriles por día, el siguiente año se extrajeron sólo 155359 barriles por día, de manera que en 1975 las exportaciones de crudo fueron más de 100000000 de dólares inferiores a las del año previo y no se exportaron derivados (véase cuadro 4). Estos factores provocaron algo que parecía imposible: un déficit en la cuenta corriente de 468900000 de dólares, equivalente a $10.9 \%$ del PIB, a escasos 42 meses de iniciadas las exportaciones de petróleo. En 1976 el déficit se redujo a $5.9 \%$ del PIB, pero el resto de la década siguió creciendo, a pesar de que el precio del petróleo también siguió ascendiendo.

Para controlar el déficit comercial se establecieron depósitos previos para las importaciones, se transfirieron bienes de la Lista I a la Lista II (en la que se debía pagar un arancel adicional de $30 \%$ sobre el valor CIF), y se prohibió en forma temporal la importación de automóviles y otros bienes considerados no esenciales (Decreto supremo número 738) 15 Estas medidas, aplicadas con la primera intención de controlar el déficit comercial, fueron presentadas como un punto de inflexión, para profundizar la industrialización dirigida por el Estado. Pero fueron duramente criticadas y la noche del 31 de agosto de 1975 el general Raúl González Alvear intentó un golpe de Estado contra el general Rodríguez Lara. En esa fracasada asonada murieron 22 personas, pero la retórica nacionalista quedó herida de muerte.

Rodríguez Lara fue relevado por un consejo supremo de gobierno compuesto por otros tres militares (12 de enero de 1976). Este consejo comenzó su gestión esterilizando el decreto supremo número 738. También suspendió la vigencia del Comité de Crédito Externo (decreto supremo número 1043, del 30 de diciembre de 1976). El sector privado comenzó a cuestionar el intervencionismo público, conductor de la industrialización. La presión empresarial logró el restablecimiento de la representación corporativa de terratenientes, industriales, comerciantes y banqueros en instituciones clave del Estado.

El nuevo gobierno se mostró más permisivo con las empresas petroleras extranjeras y redujo el impuesto a la exportación de crudo. El salario mínimo fue congelado en 1750 sucres, mientras la inflación se mantuvo sobre el $10 \%$ anual hasta el final de esa década. También se flexibilizó la decisión 24 del acuerdo de Cartagena en el tratamiento a la inversión extranjera de fuera del Pacto Andino.

\footnotetext{
${ }^{15}$ Estas herramientas de política cambiaria fueron desarrolladas y perfeccionadas en la fase de industrialización sustitutiva iniciada luego de la primera gran guerra europea.
} 
A pesar de estos cambios, la resolución de la crisis de 1975 siguió una trayectoria de continuidad, expresada en el sostenimiento del tipo de cambio. El déficit externo persistió durante el resto de la década, hasta desembocar en una aguda y generalizada crisis de deuda, de dimensiones regionales, que dio inicio a la década perdida y, en Ecuador, al proceso de sucretización de la deuda externa privada en $1 9 8 3 \longdiv { 1 6 }$

\section{El terremoto de marzo de 1987}

El gobierno de Febres Cordero (1984-1988) fue, en opinión de los expertos, ejecutor del primer ajuste macroeconómico mediante un conjunto coherente de políticas ortodoxas. En los primeros dos años aplicó una política de choque, según los lineamientos del Fondo Monetario Internacional. El Plan de Estabilización Económica iniciado el 4 de septiembre de 1984 dispuso reducir el gasto fiscal, contraer el crédito a la banca privada y una vigilada expansión de la oferta monetaria, con el fin de controlar la inflación. La reforma a la Ley General de Bancos (agosto de 1985) liberalizó las actividades bancarias y facilitó la concentración del capital financiero.

El sucre se devaluó en dos ocasiones (a 96 sucres por dólar, en septiembre de 1984 y $43 \%$ adicional en noviembre de 1985). La Junta Monetaria del BCE modificó a su antojo las listas de importación para acelerar la apertura comercial y propiciar que la mayoría de las transacciones internacionales se realice en el mercado libre de cambios.

Este ajuste detuvo el crecimiento de la economía, pero anuló el déficit de cuenta corriente, reduciéndolo a 13000000 de dólares. Se alcanzó un superávit comercial de 1205 millones de dólares, y un superávit de caja en el presupuesto general del Estado de 22000000 de sucres (Oleas, 2013, p. 133), que no pudieron mantenerse debido a dos factores exógenos: a partir de 1985 se produjo un significativo descenso de los precios del petróleo (véase cuadro 6), y el 5 de marzo de 1987 se interrumpió la exportación de crudo durante cinco meses, por consecuencia de dos terremotos ocurridos en el Nororiente ecuatoriano.

En julio de 1986 el petróleo bajó a 8 dólares por barril y en enero de 1987 se suspendió el pago de la deuda externa negociada dos años antes. Una vez más, el descenso del precio internacional del principal producto de exportación sumió al país en una nueva crisis de cuenta corriente, que se agravó con los terremotos de marzo de 1987 ${ }^{17}$ El gobierno declaró el estado de emergencia, se negoció con el Banco Mundial un préstamo de 80000000 de dólares para reconstruir la infraestructura petrolera y se recibió ayuda de Nigeria, Venezuela y Colombia.

En esas circunstancias, la ortodoxia profesada por el equipo económico del gobierno aconsejaba reducir el crédito para adaptarlo a las nuevas e inesperadas condiciones de la producción. Meses antes de la catástrofe, Carlos Julio Emanuel (1985), gerente del BCE, declaró que "se ha implantado, desde enero de 1985, una política monetaria ortodoxa [...] que permita que la economía crezca de acuerdo a su potencial, sin que se generen presiones inflacionarias" (p. 27). Pero, contradicien-

\footnotetext{
${ }^{16}$ La sucretización fue el proceso mediante el cual el Estado ecuatoriano asumió alrededor de 1600 millones de dólares de deuda externa privada. Los gobiernos que la ejecutaron la justificaron en la necesidad de evitar la pérdida de empleos.

${ }^{17}$ La noche del 5 de marzo de 1987 ocurrieron dos sismos de magnitud 6.1 y 6.9 en la escala de Richter, respectivamente, con epicentro en la provincia del Napo, 25 kilómetros al norte del volcán Reventador. Los sismos, los deslizamientos de tierra y las inundaciones provocaron decenas de muertos. También afectaron 70 kilómetros del oleoducto transecuatoriano y varias estaciones de bombeo y despresurización. El oleoducto fue totalmente destruido en un tramo de 5 kilómetros. Los costos directos e inmediatos de estos terremotos se estimaron en alrededor de 780000000 de dólares.
} 
CUADRO 6. EXPORTACIONES DE PETRÓLEO Y DERIVADOS, 1984-1988

\begin{tabular}{lccccc}
\hline & 1984 & 1985 & 1986 & 1987 & 1988 \\
\hline \multicolumn{5}{c}{ Crudo } \\
Volumen $^{\mathrm{a}}$ & 61.8 & 70.6 & 71.4 & 45.4 & 69.0 \\
Valor $^{\mathrm{b}}$ & 1678.2 & 1824.7 & 912.4 & 739.4 & 875.2 \\
Dólares po barril $^{\mathrm{c}}$ & 27.4 & 25.9 & 12.8 & 16.3 & 12.7 \\
\multicolumn{5}{c}{ Derivados } \\
Volumen $^{\mathrm{a}}$ & 6.2 & 4.8 & 6.7 & 5.7 & 9.6 \\
Valor $^{\mathrm{b}}$ & 156.3 & 101.9 & 70.1 & 78.2 & 100.5 \\
Dólares por barril $^{\mathrm{c}}$ & 25.2 & 21.0 & 10.5 & 13.7 & 10.5 \\
Valor total $^{\mathrm{b}}$ & 1834.5 & 1926.6 & 982.5 & 817.6 & 975.7 \\
\hline
\end{tabular}

${ }^{\mathrm{a}}$ Millones de barriles. ${ }^{\mathrm{b}}$ Millones de dólares. ${ }^{\mathrm{c}}$ Promedio anual.

Fuente: Oleas (2013).

do este canon económico, en 1987 la oferta monetaria 18 creció $32.3 \%$, mientras el PIB se contrajo en $6 \%$. El cuasidinero del sistema bancario creció $46.3 \%$ y la inflación sólo subió a $32.5 \%$ anual (Oleas, 2013, p. 141). Pero las decisiones monetarias y crediticias tomadas luego del terremoto almacenaron el combustible para que los precios sigan subiendo.

El gobierno obligó al BCE a emitir dinero en forma inorgánica, con lo que 21 meses después del terremoto la variación anual del índice de precios alcanzó un inédito 75.6\%. La expansión monetaria provocó inflación, vació la reserva monetaria internacional y el déficit del sector público no financiero subió hasta $4.1 \%$ del PIB (Oleas, 2013, pp. 144, 414).

Luego del terremoto la ortodoxia se transformó en clientelismo. Es decir, la crisis provocada por el terremoto interrumpió -rompió temporalmente- la cadencia de ajustes ortodoxos iniciados en 1982 por el presidente Hurtado y continuados durante los gobiernos de Borja y Durán Ballén. El déficit fiscal se disparó hasta 10 \% del PIB, con Febres Cordero dedicado a promover obras públicas, en especial en Guayaquil y su zona de influencia. El crédito neto a los bancos privados se contrajo en 28527 millones de sucres, mientras que el BCE concedió al gobierno créditos por 16000 millones de sucres, con lo que el crédito neto al sector público se incrementó en 18136 millones de sucres (Oleas, 2013, p. 144).

En agosto de 1988 la reserva monetaria internacional registró un saldo negativo de 330000000 de dólares y la inflación cerró el periodo de gobierno en $66 \%$ anual. La liberalización cambiaria fue revertida, mientras el nerviosismo y la especulación ampliaron a $109 \%$ la diferencia entre el tipo de cambio de intervención y el de mercado libre (Oleas, 2013, p. 145).

${ }^{18}$ Especies monetarias en circulación más depósitos monetarios en los bancos. 


\section{CRISIS ESPECUlativas DE FINES DEL SIGLO XX}

La década final del siglo xx presenció el avance incontenible de la segunda ola de globalización del capital. En 1989 varios economistas propusieron diez recomendaciones de política económica para países en desarrollo compendiadas por John Williamson en lo que al poco tiempo se llamó el Consenso de Washington. En noviembre de ese año cayó el muro de Berlín y, con la disolución de la URSS (diciembre de 1991), terminó la Guerra Fría. Francis Fukuyama (1992) proclamó el fin de la historia, una nueva etapa en la que la democracia liberal prevalecería en el mundo entero.

Tras una década de intermitentes ajustes recesivos, en Ecuador el tipo de cambio (sucres por dólar) se había convertido en la variable económica más importante, persistía una inflación de dos dígitos altos, la deuda externa seguía siendo un problema grave y estaban pendientes todas las "reformas de segunda generación” aconsejadas por el Consenso de Washington, salvo la desgravación arancelaria y la liberalización del mercado de trabajo emprendidas al final del gobierno de Borja. Mientras en la economía las "expectativas racionales" parecían explicarlo todo, la política nacional comenzó a derivar hacia un estado de anomia provocado por los efectos sociales de los sucesivos paquetazos y por la creciente distancia que separaba a la gente común de mandatarios cada vez mejor cooptados por los grupos económicos dominantes.

Expectativas y especulación son como las dos caras de una misma moneda, y se encuentran en el centro de los frecuentes eventos críticos de fines del siglo xx. Este trabajo aborda dos de ellos. El primero, ocurrido en 1992, a la luz del proceso eleccionario que llevó a la presidencia de la república a Sixto Durán Ballén. Este evento configuró las pautas fundamentales de los frecuentes ataques especulativos ocurridos en esa década, facilitados por la mecánica de ajuste macroeconómico, que relacionaba al tipo de cambio con la tasa de interés (interna e internacional) y con la inflación (interna e internacional). El segundo se incubó con más lentitud, desde la reforma a la Ley de Régimen Monetario que entró en vigor “por el ministerio de la ley”, al final del mandato de Borja; dio su primera advertencia entre 1995 y 1996, cuando quebró el Banco Continental, y finalmente se transformó en la más aguda crisis económica y financiera de la azarosa historia económica ecuatoriana.

\section{El ataque a la reserva internacional en las elecciones de 1992}

En 1992 Ecuador vivió una intensa y costosa campaña electoral que enfrentó a dos partidos de derecha. La campaña alteró las expectativas sobre la cotización futura del dólar, la variable más importante para empresarios, exportadores e importadores. A pesar de una década de ajustes la inflación era de dos dígitos altos; la deuda externa creció, en parte porque se la dejó de pagar desde enero de 1987, y en parte porque Borja nunca llegó a un acuerdo con los acreedores. El gobierno saliente se había esforzado en fortalecer el sector externo, gracias a un nuevo repunte del precio del petróleo, lo que se expresó en un cómodo stock de reservas internacionales 19 Todos esperaban un nuevo ajuste macroeconómico, quienquiera que ganase las elecciones 20

\footnotetext{
${ }^{19}$ En agosto de 1989 Irak invadió Kuwait, justificando su ataque en la explotación por parte de Kuwait de un campo petrolero compartido. El Consejo de Seguridad de las Naciones Unidas sancionó a Irak prohibiendo a los demás países comprar su petróleo. Esto provocó subidas esporádicas del crudo hasta 40 dólares por barril, que no se pudieron mantener en el tiempo gracias a la compensación de producción de los países árabes y a las previsiones tomadas por la Agencia Internacional de Energía, como el mayor nivel de reservas y la reducción del uso de petróleo en la producción de los países de la Organización para la Cooperación y el Desarrollo Económicos (Oleas, 2013, p. 192).

${ }^{20}$ El candidato del Partido Unidad Republicana, Sixto Durán, o el del Partido Social Cristiano, Jaime Nebot.
} 
En medio de la campaña, según un vocero oficial del Banco de Guayaquil, el sistema financiero adolecía de "marcada iliquidez" debido a que a fines de junio el gobierno retiró unos 30000 millones de sucres de la banca privada y los depositó en el BCE. Ese banquero también señaló que existía un "sobre stock de importaciones [para anticiparse a] una futura devaluación que tendrá que hacer el nuevo gobierno [y que al mismo tiempo] el exportador está tratando de retrasar sus exportaciones o disminuir sus anticipos a futuras exportaciones previendo una mejor liquidez producto de una devaluación futura.'21

Como todos esperaban la devaluación, quienes podían comenzaron a comprar dólares. El BCE sabía que algunos bancos se habían dedicado a especular contra el sucre, lo que provocó una escalada de la tasa de interés interbancaria a $110 \%$, mientras el gobierno saliente trataba de mantener la cotización de la divisa. Varias entidades privadas se desencajaron. El gobierno había logrado que la reserva monetaria internacional subiera de 103000000 de dólares en enero de 1990 (menos de un mes de importaciones) a 760000000 de dólares en diciembre de 1991 (cuatro y medio meses de importaciones).

Mientras se desarrollaba la campaña electoral, la especulación cambiaria drenó de la reserva monetaria internacional más de 420000000 de dólares y, para agosto de 1992, esta se había reducido a 224000000 de dólares, es decir, menos de mes y medio de importaciones (Oleas, 2013, p. 195). Durán ganó las elecciones con 57.9 \% de los votos válidos y el 3 de septiembre de 1992 ejecutó un ajuste sin precedentes. Se decretó una macrodevaluación monetaria, se redujo el gasto fiscal y elevó las tarifas de varios servicios públicos y de los combustibles. El ajuste frenó la inflación, pero detuvo el crecimiento, promovió el ingreso de capitales golondrina que hicieron más difícil la estabilización económica, y suscitó un ambiente especulativo y cortoplacista adverso a la inversión productiva.

Este plan continuó el modelo de ajuste macroeconómico auspiciado por el FMI, pero perfeccionándolo con un ancla cambiaria. El sucre se devaluó $35 \%$ en relación con el dólar estadunidense, se modificó el sistema cambiario y en octubre el dólar del BCE se cotizó en 2000 sucres para la compra y la venta, es decir $5.6 \%$ más caro que en el mercado libre. Los importadores podían adquirir dólares a ese precio en el mercado de intervención o en el mercado libre, pero a los exportadores privados se les obligó a vender sus divisas al BCE y a cambio recibían $85 \%$ en efectivo (1 700 sucres) y $15 \%$ en un bono cambiario cero-cupón, a 180 días plazo, denominado en dólares y de libre negociación (Oleas, 2013, pp. 201-202).

El gasto presupuestario del Estado se redujo en 70000 millones de sucres, lo que prácticamente eliminó el déficit del sector público no financiero. Se elevaron las tarifas de energía eléctrica ( $120 \%$ en promedio) y los precios de los combustibles (115\% en promedio), y se creó el impuesto especial a los activos de las empresas -vigente desde diciembre de 1992. Desde la visión ortodoxa, este ajuste pareció exitoso, pues se cumplieron todos los objetivos propuestos (véase cuadro 7). Pero en 1993 el PIB sólo creció 2 \%, la tasa más baja desde 1987, el consumo final del gobierno se redujo $1.2 \%$ y la inversión del gobierno bajó $11.3 \%$ (véase cuadro 8 ).

Esta crisis especulativa, y el overshooting cambiario con el que se la resolvió, tuvieron consecuencias de corto y de largo plazo. Aliviadas las expectativas cambiarias, regresaron los capitales, se recuperó la reserva internacional y se fortaleció la monetización de la economía. El dinero se volvió endógeno, la inflación demoró dos años en bajar a $25 \%$ y la tasa de interés se tornó muy inestable. Esto promovió las conductas especulativas de los empresarios y en general inhibió la

${ }^{21}$ El Comercio, 13 de julio de 1992, p. A-15. 


\section{CUADRO 7. RESUMEN DE RESULTADOS}

DEL PLAN MACROECONÓMICO, 1992-1993

\begin{tabular}{|c|c|c|c|}
\hline & \multirow[t]{2}{*}{1992} & \multicolumn{2}{|c|}{1993} \\
\hline & & Objetivo & Resultado \\
\hline Inflación (a diciembre de cada año) & $60 \%$ & $30 \%$ & $31 \%$ \\
\hline $\begin{array}{l}\text { Reserva monetaria internacional } \\
\text { (millones de dólares estadunidenses) }\end{array}$ & 782 & 1042 & 1252 \\
\hline Déficit del sector público no financiero & $-1.7 \%$ & $-0.5 \%$ & $-0.4 \%$ \\
\hline $\begin{array}{l}\text { Crédito neto al sector público no financiero } \\
\text { (millones de sucres) }\end{array}$ & -1182 & -1959 & -2034 \\
\hline Crecimiento del PIB & $3.6 \%$ & $2.2 \%$ & $2.0 \%$ \\
\hline
\end{tabular}

Fuente: Banco Central del Ecuador (1993).

inversión productiva. También marcó el inicio de la dolarización de los depósitos de los agentes económicos y una etapa de especulación contra el tipo de cambio anunciado por el BCE, que sólo terminó con la pérdida de la política monetaria, el 9 de enero de 2000.

Tal vez el efecto más pernicioso de esta especulación fue el notorio cambio que sufrieron las preferencias de los agentes económicos, enfrentados por la lógica del ajuste con ancla cambiaria a especular en medio de un trilema (tipo de cambio, tasas de interés nominales e inflación esperada) que se agudizó conforme tomaba cuerpo la crisis final del siglo xx.

Crisis moral y comercial al final del siglo $\mathrm{XX}$

La Ley General de Instituciones del Sistema Financiero (1994) garantizaba el libre flujo de divisas y capitales, según lo prescribía el Consenso de Washington ${ }^{22}$ En febrero de 1996 las autoridades financieras constataron que, en tres meses, desde noviembre de 1995, habían salido del Banco Continental 300000000 de dólares. El 20 de marzo la Junta Monetaria autorizó un crédito subordinado por 121700000 de dólares para salvar al mismo Banco Continental. Días más tarde la prensa especializada denunció que un aumento del capital registrado en noviembre de 1995, por 42300000 de dólares, se había contabilizado gracias a un crédito ficticio del Banco Continental Overseas de Curaçao, con el que se había inflado el patrimonio de la matriz en Ecuador. Ambas entidades, la de Ecuador y la de Curaçao, pertenecían al holding Conticorp. El presidente del Banco Continental fue removido de su cargo el 16 de mayo y en junio el BCE constató que, en medio de juegos financieros y préstamos subordinados, habían desaparecido más de 100000000 de dólares (Oleas, 2013, pp. 277-278).

\footnotetext{
${ }^{22} \mathrm{El}$ párrafo 42 de la carta de intención remitida al director-gerente del Fondo Monetario Internacional, Michel Camdessus, el 31 de marzo de 1994, anticipó que el ejecutivo remitiría al Congreso, hasta mayo de ese año, una Ley General de Instituciones Financieras que busca "mejorar la eficiencia de la intermediación financiera, fortalecerá la supervisión y regulación bancaria, permitirá la creación de la banca múltiple y estandarizar las normas para los diversos tipos de instituciones financieras" (Oleas, 2013, p. 473).
} 


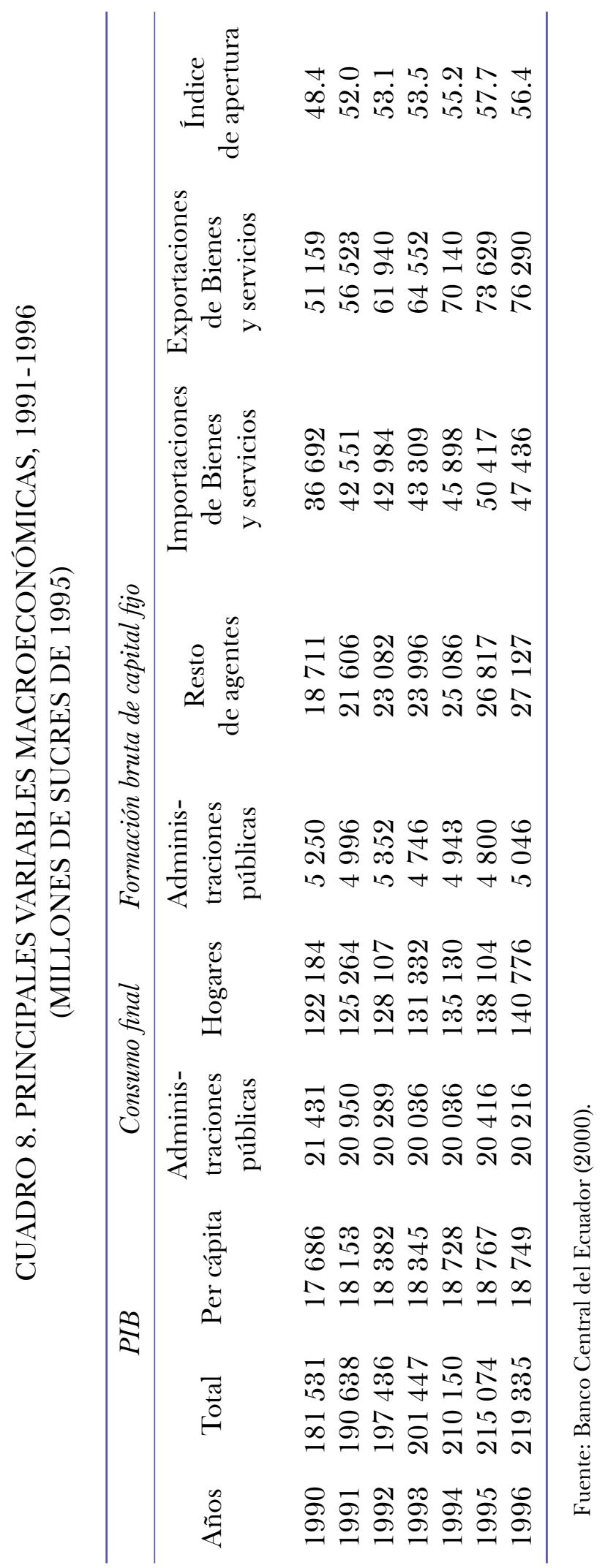


Este evento puede considerarse como el inicio de la crisis financiera de finales del siglo xx. Las autoridades económicas (Ministerio de Finanzas, Superintendencia de Bancos, BCE y juntas Bancaria y Monetaria) justificaron su decisión en la necesidad de evitar el riesgo sistémico que provocó un efecto dominó entre las entidades del sistema financiero. Pero al tomar esa decisión inauguraron la fase de riesgo moral ${ }^{23}$ que en los próximos cinco años contribuiría a aniquilar la mitad del sistema financiero nacional, a amputar la política monetaria y a retrotraer el bienestar general de los ecuatorianos a condiciones similares a las de 198024

Este episodio mostró la penetración de los intereses privados en las decisiones de las autoridades monetarias y financieras, y agravó la inestabilidad política empezada cuando el vicepresidente Dahik, gestor intelectual de las reformas promercado iniciadas diez años atrás, abandonó el país apresuradamente en octubre de 2015. El presidente electo en agosto de 1996, Abdalá Bucaram, fue derrocado a los seis meses de asumir su cargo; le sucedió Fabián Alarcón, interino que durante 18 meses preparó un nuevo proceso electoral, en el que Jamil Mahuad ganó el balotaje a Álvaro Noboa, con un estrecho $51.2 \%$ de los votos. Mahuad duró en su cargo otros 18 meses y fue depuesto en enero de 2000. Esta inestabilidad se desarrolló en forma paralela a una incertidumbre jurídica que no pudo ser revertida ni por la masiva reforma a la Constitución de 1979 elaborada en la Academia de Guerra de Sangolquí en 1998.

La Ley General de Instituciones del Sistema Financiero propició esta anómala condición del mercado financiero y dio inicio a la dolarización del país (véase cuadro 9). Este proceso se conjugó con dos eventos exógenos: el fenómeno climático de El Niño de 1997-1998 y una aguda disminución del precio de las materias primas exportadas por Ecuador, que indujeron una nueva crisis de cuenta corriente.

Desde junio de 1997 El Niño provocó desajustes climáticos y pérdidas de vidas humanas y económicas. El fenómeno afectó a 60 \% de la población ecuatoriana; entre octubre de 1997 y junio de 1998 fallecieron 292 personas por causas relacionadas con él, desaparecieron otras 40 y 162 resultaron heridas. Los casos de malaria incrementaron a $63 \%$ y los de cólera a $253 \%$. Unos $2547 \mathrm{~km}$ de carreteras principales, $5975 \mathrm{~km}$ de vías secundarias y $2935 \mathrm{~km}$ de vías de tercer orden, así como muchos de sus puentes, sufrieron daños directos e indirectos (Oleas, 2013, pp. 315-316).

En el sector productivo las pérdidas habrían alcanzado los 1421 millones de dólares. El lucro cesante habría sido de $8 \%$ del PIB y las pérdidas en infraestructura representaron $7 \%$ de la formación bruta de capital fijo nacional. El impacto negativo en la balanza comercial se estimó en 721000000 de dólares, como resultado de la combinación de una cantidad mayor de importaciones (420 000000 de dólares) con una menor de exportaciones (300 000000 de dólares). Para reconstruir los daños causados por el fenómeno se debía invertir unos 2200 millones de dólares (Oleas, 2013, p. 316).

\footnotetext{
23 ¿Qué mismo pasó con el Continental? (abril de 1996). Gestión, Economía y Sociedad, 22, pp. 16-21.

${ }^{24}$ El riesgo moral ocurre cuando un agente económico tiene comportamientos oportunistas, buscando su propio beneficio a costa de otra parte que no puede conocer o estar informada de su conducta. Aparece en mercados con información asimétrica, es decir, que una de las partes conoce perfectamente las motivaciones de su conducta, mientras los otros no pueden saberlas. Cuando el regulador del mercado financiero es capturado por quienes incurren en riesgo moral, se potencia su efecto pernicioso y se hace más fácil incurrir en "selección adversa", es decir la situación en la que el contratante de un contrato de depósito no es capaz de valorar si el prestador de ese servicio -el banco- es un agente financiero confiable.
} 
CUADRO 9. DOLARIZACIÓN DE LA ECONOMÍA ECUATORIANA, 1990-1999. PORGENTAJE DEL AGREGADO TOTAL CORRESPONDIENTE

\begin{tabular}{ccccc}
\hline Año $^{2}$ & Fondos disponibles $^{\mathrm{a}}$ & Cuasidinero $^{\mathrm{a}}$ & Ahorro $^{\mathrm{b}}$ & Crédito $^{\mathrm{c}}$ \\
\hline 1990 & 29.3 & 7.5 & 0.1 & 1.6 \\
1991 & 30.4 & 7.6 & 0.3 & 3.0 \\
1992 & 37.8 & 10.9 & 2.4 & 6.8 \\
1993 & 32.0 & 12.6 & 4.5 & 13.5 \\
1994 & 44.1 & 15.7 & 8.1 & 19.9 \\
1995 & 59.2 & 24.3 & 18.5 & 28.3 \\
1996 & 63.7 & 28.0 & 23.7 & 32.8 \\
1997 & 63.1 & 36.9 & 33.6 & 44.7 \\
1998 & 46.1 & 43.7 & 39.6 & 58.9 \\
$1999 \mathrm{~d}$ & 60.1 & 59.3 & 56.1 & 66.5 \\
\hline
\end{tabular}

\footnotetext{
${ }^{a}$ En el sistema de bancos privados. ${ }^{b}$ Ahorro en el sistema financiero nacional valorado a la cotización de venta del mercado de intervención vigente al 31 de diciembre de cada año. ${ }^{c}$ Cartera valorada a 10900 sucres por dólar. ${ }^{\mathrm{d}}$ Hasta noviembre de 1999, para las variables monetarias.

Fuente: Oleas (2013).
}

En 1998 el precio promedio del crudo ecuatoriano descendió a 9.2 dólares por barril y el volumen exportado se redujo $6.1 \%$, debido a la necesidad de más combustible para las plantas de termogeneración. La importación de derivados saltó de 6600000 de barriles en 1996 a 15300000 en 1998. Mientras el precio del crudo ecuatoriano se redujo $49 \%$ entre 1996 y 1998, el precio de los derivados sólo disminuyó 13.4 \%, con el consiguiente impacto en la cuenta corriente (Oleas, 2013, pp. 309-313).

Ese año las exportaciones disminuyeron $3.2 \%$. Con excepción del cacao, los precios internacionales de los principales productos de exportación bajaron, así como sus volúmenes exportados. Pero las importaciones de bienes y servicios crecieron $5.5 \%$ debido a la necesidad de sustituir los productos alimenticios no cultivados por causa de El Niño, y de materias primas y bienes de capital para la industria. Con la crisis financiera de Asia los productos provenientes de esos países ganaron competitividad. La agudización de la crisis económica en Rusia perjudicó las exportaciones agrícolas de flores y banano. Con estas restricciones la cuenta corriente alcanzó un déficit de $9.3 \%$ del PIB, equivalente a 2169 millones de dólares, el más alto de la década final del siglo xx (véase cuadro 10 .

La dolarización de los agregados monetarios y de varios tipos de transacciones comerciales redujo la efectividad de la política monetaria, limitó las opciones de política cambiaria y exacerbó el riesgo cambiario de las entidades financieras, dadas las condiciones de crisis interna e internacional. En 1999 la crisis financiera, agravada por el feriado bancario ${ }^{25}$ la anomia social promovida por la desidia del gobierno y, sobre todo, el congelamiento de los depósitos en el sistema financiero y el decrecimiento esperado de la producción, hicieron caer las importaciones por primera vez en

\footnotetext{
${ }^{25}$ Interrupción, autorizada por el gobierno, de la atención del sistema financiero a sus clientes durante cinco días, del 8 al 12 de marzo de 1999.
} 
GUADRO 10. INDICADORES ECONÓMICOS SELECGIONADOS, 1995-1999

\begin{tabular}{lccccc}
\hline Indicadores económicos & 1995 & 1996 & 1997 & 1998 & 1999 \\
\hline PIB $^{\mathrm{a}}$ & 2.3 & 2.0 & 3.4 & 0.4 & -7.3 \\
Saldo en cuenta corriente $^{\mathrm{c}}$ & -3.6 & 0.5 & -3.0 & -9.3 & 5.7 \\
Exportaciones $^{\mathrm{a}}$ & 5.0 & 3.6 & 4.3 & -3.2 & -0.4 \\
Importaciones $^{\mathrm{a}}$ & 2.3 & 2.0 & 3.4 & 0.4 & $-7,3$ \\
Reserva monetaria internacional $^{\mathrm{b}}$ & 1557 & 1831 & 2093 & 1698 & 1276 \\
Deuda externa $^{\mathrm{c}}$ & 69.0 & 68.6 & 63.9 & 70.5 & 97.6 \\
Sector público no financiero $^{\mathrm{d}}$ & -1.4 & -3.1 & -2.6 & -6.0 & -4.9 \\
Ingresos petroleros $^{\mathrm{d}}$ & 7.4 & 8.2 & 6.4 & 4.6 & 7.6 \\
Ingresos no petroleros $^{\mathrm{d}}$ & 15.1 & 13.6 & 15.8 & 15.6 & 16.8 \\
Gasto corriente $^{\mathrm{d}}$ & 20.1 & 19.7 & 20.0 & 20.1 & 22.8 \\
Tipo de cambio $^{\mathrm{e}}$ & 26.9 & 23.1 & 22.3 & 49.8 & 175.6 \\
Inflación $^{\mathrm{e}}$ & 22.8 & 25.5 & 30.7 & 43.4 & 60.7 \\
Petróleo $^{\mathrm{f}}$ & 14.8 & 18 & 15.4 & 9.2 & 15.5 \\
\hline
\end{tabular}

\footnotetext{
${ }^{\mathrm{a}}$ Variación anual (sucres de 1975). ${ }^{\mathrm{b}}$ Millones de dólares. ${ }^{\mathrm{c}}$ Porcentaje del PIB. ${ }^{\mathrm{d}}$ Resultado global como porcentaje del PIB. ${ }^{\mathrm{e}}$ Tasa porcentual de variación anual. ${ }^{\mathrm{f}}$ Dólares por barril, promedio anual.

Fuentes: Oleas (2013).
}

quince años. Los precios de los productos de exportación siguieron cayendo, con excepción del petróleo, que subió a 15.5 dólares por barril, con lo que el año final del siglo cerró con un superávit de cuenta corriente de 955000000 de dólares.

En esta crisis los problemas de la cuenta corriente de 1998 fueron un factor menos gravitante que la condición de los portafolios de los agentes económicos, tras casi una década de paulatina sustitución de la moneda nacional (el sucre) por la moneda estadunidense, en condiciones de libre movilidad de capitales. En este proceso, los pasivos denominados en dólares llegaron a ser mucho más significativos que los pasivos denominados en moneda nacional (véase cuadro 9). En estas condiciones, los agentes con deudas en dólares urgieron a Mahuad a eliminar el riesgo cambiario. Dicho de otra manera, lo conminaron a dolarizar unilateralmente la economía ecuatoriana, lo que en efecto ocurrió el 9 de enero de 2000, provocando una de las más drásticas rupturas institucionales registradas en la historia económica de Ecuador.

\section{Conclusiones}

Este artículo presenta un primer acercamiento al estudio de las crisis económicas de Ecuador durante el siglo xx. Se trata de una aproximación descriptiva, con el propósito de investigar los atributos generales de siete crisis, identificadas a partir de una periodización histórica asumida ex ante. En esta caracterización se ha constatado que cuatro de ellas han sido rupturistas y tres continuistas. Queda para futuras -y extensas- investigaciones dilucidar, en el dominio de la explicación histórica, los cambios que esas crisis pudieron haber provocado en las fuerzas productivas y en las relaciones de producción de una economía periférica como la ecuatoriana. 
Se puede anticipar que las siete crisis revisadas en este artículo provocaron intensos y persistentes efectos en la economía del país, en cuanto a distribución del ingreso y retrocesos en la reducción de las brechas de desarrollo.

La periodicidad asumida parece adecuada. En el siglo xx se distinguen con claridad tres etapas. En la primera se investigan dos eventos críticos correspondientes a sendas crisis internacionales del patrón oro. En 1914 la moratoria declarada por el Banco de Inglaterra, a raíz del inicio de la primera gran guerra europea del siglo pasado, inició el fin del ciclo expansivo de exportación del cacao. Luego, en 1931-1932, el colapso final del patrón oro, también detonado por una nueva cesación de pagos del Banco de Inglaterra, que precipitó la intervención del poder ejecutivo en el BCE y el inicio de un primer ciclo expansivo de la oferta monetaria bajo el monopolio de emisión ideado por E. W. Kemmerer. Entre estas dos crisis se produjo el cambio de polaridad de la dependencia ecuatoriana respecto del centro del sistema capitalista, desde el ya decadente eje financiero de Londres hacia el emergente centro de Nueva York.

En la segunda etapa se analizan tres eventos críticos, todos relacionados con la balanza de bienes. El de 1965 fue detonado por los cambios tecnológicos del mercado mundial del banano impulsados por las transnacionales estadunidense. A partir de ese año, y a pesar de la eficaz reacción empresarial, comenzó a declinar el ciclo bananero, lo que se tradujo en un continuo déficit comercial. El de 1975 fue desencadenado por el consorcio Texaco-Gulf, en su afán de boicotear la extracción de petróleo, para oponerse al avance nacionalista de la dictadura militar. El de 19861987 fue provocado por el descenso del precio internacional del petróleo y el terremoto de marzo de 1987. Esto doblegó la inicial ortodoxia del gobierno y descubrió su carácter clientelar.

En la tercera etapa se examinan dos crisis en las que participó de manera determinante la especulación financiera, favorecida por la tendencia hacia la liberalización de las cuentas de capitales promovida por el Consenso de Washington. La de 1992 consistió en un ataque especulativo contra la reserva internacional, encabezado por el sector financiero. Esta crisis fue sofocada con la adopción de un modelo de ajuste con ancla nominal (sobre el tipo de cambio). ${ }^{26}$ En la crisis final del siglo xx concurrieron circunstancias comerciales, como la reducción de la oferta exportable y el incremento de las importaciones - provocados ambos por El Niño-, el agudo descenso de los precios del petróleo y otras materias primas exportadas por el país y, en especial, el riesgo moral instaurado desde 1996. La alteración de las variables macroeconómicas inducida por la forma de gestionar la crisis financiera fue extraordinaria, al punto que en 1999 se revirtió el déficit comercial del año previo, dado el represamiento de la demanda de importaciones y la relativa expansión de las exportaciones, alentadas por la devaluación monetaria.

La mayoría de estas crisis produjo transiciones rupturistas en la gestión de la política macroeconómica. Rápidas modificaciones de la política monetaria y cambiaria ocurrieron en 1914, con la promulgación de la Ley Moratoria; en 1932, con el fin de la convertibilidad administrada por el BCE, y en 2000, con la dolarización unilateral de la economía. La radical alteración de las políticas fiscal y monetaria luego del terremoto de 1987, también se puede considerar una transición rupturista, pues interrumpió el avance de las reformas neoconservadoras iniciadas en 1982, a raíz de la crisis de la deuda externa.

\footnotetext{
${ }^{26}$ Este modelo de ajuste, anclado al tipo de cambio nominal, permaneció vigente entre octubre de 1992 y febrero de 1999, condicionando profundamente las conductas especulativas y cortoplacistas de los agentes económicos.
} 
Las tres crisis restantes produjeron transiciones continuistas. Si bien la crisis de 1965 marcó la fase final del auge bananero y el progresivo debilitamiento de la estabilidad macroeconómica inaugurada en 1947, no alteró la lógica general de la política macroeconómica. Así mismo, la fracasada asonada de agosto de 1975 no perturbó en forma significativa la confianza desarrollista en la palanca petrolera, pero aparecieron los primeros cuestionamientos al modelo cepalino y se ampliaron las opciones de financiamiento externo. La más significativa de las transiciones continuistas se dio tras la crisis especulativa de 1992, contrarrestada mediante el overshooting cambiario de septiembre de ese año, que controló temporalmente las expectativas devaluatorias y atenuó la inercia inflacionaria desatada en 1987. En esta ocasión la lógica del ajuste macroeconómico se fortaleció y perfeccionó.

A pesar del blanqueamiento semántico propuesto por Svampa (y de acuerdo con Koselleck), el concepto crisis es adecuado para categorizar las alteraciones macroeconómicas detalladas en este artículo. Más aún, el mismo recupera significación si se lo adjetiva con nociones como cuenta corriente, especulación, boicot o El Niño.

No parecen necesarios los criterios operativos que con base en la arbitraria tipología cuantitativa de Reinhart y Rogoff (2009) siguen Bértola y Ocampo (2013). Desde una perspectiva de historia económica, el estudio de las crisis tiene complejos contenidos y causalidades políticas, sociales y económicas. $\mathrm{O}$, dicho de otra manera, cada evento en particular puede concebirse dentro de condiciones específicas de economía política que hacen preferible no circunscribirlo dentro de márgenes cuantitativos (déficit de cuenta corriente como porcentaje del PIB, tasa de decrecimiento del PIB).

El análisis de estas siete crisis remite, fatalmente, a una noción de proceso histórico carente de teleología. Luego de cada evento crítico todo, o prácticamente todo, aparenta volver a la normalidad. Las crisis estudiadas se resolvieron, en forma paulatina mediante el reacomodo de los factores subyacentes, o mediante la inesperada bonanza de un nuevo ciclo de auge exportador, o en forma violenta mediante la modificación del régimen cambiario, o incluso mediante su radicalización. Pero, los rasgos fundamentales de una estructura económica comandada por las exportaciones de bienes primarios se resisten empecinadamente al cambio.

Esta resistencia destaca la importancia de los resultados del sector externo para la normalidad macroeconómica del Ecuador del siglo xx. A diferencia de lo que solía ocurrir en las economías del centro del sistema capitalista -al menos hasta la década de 1980- donde las crisis macroeconómicas se originaban en alteraciones de la demanda agregada, las crisis de la economía ecuatoriana se originaron en cambios de las condiciones del sector externo. Esos cambios tuvieron su inicio en fluctuaciones de la demanda de las exportaciones ecuatorianas, en el colapso de los regímenes cambiarios, en cambios tecnológicos y desastres naturales, o en motivaciones políticas y distributivas que alteraron las condiciones del intercambio internacional. Parafraseando a Germánico Salgado (1978), pp. 26-27, si por cualquiera de estos factores las exportaciones dejaban de hinchar las velas del navío, el casco se detenía, iniciaba la deriva y sobrevenía la crisis. Esta constatación remite a la necesidad de evaluar las perspectivas teóricas desde las cuales se enfrentaron esas crisis. Es decir, a identificar la matriz o matrices conceptuales desde las cuales se las conjuró, así como a revisar la pedagogía económica relacionada a ellas. También queda pendiente el análisis de las mecánicas disciplinarias y de los cambios en las fuerzas productivas y en las relaciones de producción aprovechadas por el capital para reestructurarse en los eventos de crisis. Lo que confirma el carácter exploratorio de este trabajo. 


\section{LISTA DE REFERENCIAS}

Alexander, L. (1992). Las finanzas públicas en el Ecuador (1830-1940). Quito: Banco Central de Ecuador.

Almeida, P. y Almeida, R. (1988). Estadísticas económicas históricas, 1948-1983. Quito: Banco Central del Ecuador/Centro de Investigación y Cultura.

Banco Central del Ecuador (1933). Memoria anual. Quito: Autor.

Banco Central del Ecuador (1997). Setenta años de información estadística. Quito: Autor/Dirección General de Estudios.

Banco Central del Ecuador (2000). Boletín anuario, 22.

Bértola, L. y Ocampo, J. A. (2013). El desarrollo económico de América Latina desde la Independencia. México: Fondo de Cultura Económica.

Carbo, L. A. (1978). Historia monetaria y cambiaria del Ecuador. Desde la época colonial. Quito: Banco Central del Ecuador.

Chiriboga, M. (2013). Jornaleros, grandes propietarios, y exportación cacaotera 1790-1925. Quito: Corporación Editora Nacional.

Corden, W. M. y Neary, J. P. (1982). Booming sector and de-industrialisation in a small open economy. The Economic Journal, 92(368), 825-848. DoI: 10.2307/2232670

Cárdenas, J. (1995). Ensayo histórico de la economía ecuatoriana. Quito: Banco Central del Ecuador.

Emanuel, C. J. (1985). Conferencia del doctor Carlos Julio Emanuel, sobre el tema: deuda externa y políticas de ajuste. Seminario crisis económica y perspectivas de desarrollo en América Latina. Quito: Banco Central de Ecuador.

Fukuyama, F. (1992). El fin de la historia y el último hombre. Bogotá: Planeta.

Larrea, C. (ed.). (1987). El banano en el Ecuador. Transnacionales, modernización y desarrollo. Quito: Corporación Editora Nacional.

Naranjo, M. (2006). Auge petrolero y enfermedad holandesa en Ecuador. En G. Fontaine (ed.), Petróleo y desarrollo sostenible en Ecuador 3. Las ganancias y pérdidas. Quito: Facultad Latinoamericana de Ciencias Sociales.

O’Connor, J. (1988). Capitalism, nature, socialism a theoretical introduction. Capitalism Nature Socialism, 1(1), 11-38. DoI: $10.1080 / 10455758809358356$

Oleas, J. (1995a). La política económica del Banco Central del Ecuador: Ciclos recesivo y expansivo de política monetaria y control del tipo de cambio: 1927-1937 (Tesis de maestría). Facultad Latinoamericana de Ciencias Sociales, Quito.

Oleas, J. (1995b). Política ecuatoriana expansiva y suspensión del patrón oro. Revista Ecuatoriana de Historia Económica, 12.

Oleas, J. (2004). Economía republicana, 1830-2001. En J. Ponce (ed.), Enciclopedia Ecuador a su alcance. Bogotá: Espasa.

Oleas, J. (2013). Ecuador 1972-1999: del desarrollismo petrolero al ajuste neoliberal (Tesis doctoral). Universidad Andina Simón Bolívar, Quito.

Reinhart, C. M. y Rogoff, K. S. (2009). This time is different: eight centuries of financial folly. Princeton: Princeton University Press.

Salgado, G. (1978). Lo que fuimos y lo que somos. En G. Drekonia (ed.), Ecuador: hoy. Bogotá: Siglo XXI Editores.

Sardi, E. (2012). Enfermedad holandesa. Recuperado de https://www.portafolio.co/opinion/emilipsardi/enfermedad-holandesa-110528 
Singer, H. W. (1950). The distribution of gains between investing and borrowing countries. The American Economic Review, 40(2), 473-485.

Svampa, L. (2016). El concepto de crisis en Reinhart Koselleck. Polisemias de una categoría histórica. Anacronismo e irrupción. Revista de teoría y filosofía clásica y moderna, 6(11), 131-151.

Torre, A. (1987). Macroeconomic aspects of a petroleum boom: Ecuador, 1972-1980 (Tesis doctoral). University of Notre Dame, Estados Unidos.

Urquidi, V. y Thorp, R. (1976). América Latina en la economía internacional. México: Fondo de Cultura Económica.

Hemerografía

El Comercio, Quito, Ecuador.

El Telégrafo, Guayaquil, Ecuador. 